Tropical Journal of Pharmaceutical Research December 2020; 19 (12): 2577-2582

ISSN: $1596-5996$ (print); 1596-9827 (electronic)

(C) Pharmacotherapy Group, Faculty of Pharmacy, University of Benin, Benin City, 300001 Nigeria.

Available online at http://www.tjpr.org

Original Research Article

http://dx.doi.org/10.4314/tjpr.v19i12.14

\title{
Yiqi Gubiao pill alleviates chronic obstructive pulmonary disease in rats via upregulation of klotho expression
}

\author{
Zheng $\mathrm{Li}^{1,2}$, Jing Wang ${ }^{1-3}$, Dan $\mathrm{Xu}^{1,2}$, Jing Jing ${ }^{1,2}$, Fengsen $\mathrm{Li}^{1,2 *}$ \\ ${ }^{1}$ The Traditional Chinese Medicine Hospital Affiliated to Xinjiang Medical University, ${ }^{2}$ National Clinical Research Base of \\ Traditional Chinese Medicine in Xinjiang, ${ }^{3}$ Key Laboratory of Xinjiang Uygur Autonomous Region (Respiratory Disease), \\ Urumqi, PR China
}

*For correspondence: Email: cypya9@163.com

Sent for review: 30 August 2020

Revised accepted: 24 November 2020

\begin{abstract}
Purpose: To investigate the effect of Yiqi Gubiao pill (YGP) on chronic obstructive pulmonary disease $(C O P D)$ in rats, and the mechanism of its action.

Methods: Six groups of eight-week old male SPF-grade Wistar rats $(n=60)$ were used (10 rats/group), viz, control, COPD, low-dose YGP, medium-dose YGP, high-dose YGP, and dexamethasone groups. Chronic obstructive pulmonary disease (COPD) was induced using a standard method. Graded doses of YGP were prepared by dissolving 100, 200 or 400 pills of Yiqi Gubiao. Lung damage and airway remodeling were determined by histological examination. Enzyme-linked immunosorbent assay (ELISA) was used to measure levels of klotho in rat serum and bronchoalveolar lavage fluid (BALF). The MRNA and protein expressions of klotho in lung tissue were assayed with qRT-PCR) and Western blot assay, respectively.

Results: Serum and BALF klotho levels were significantly lower in COPD rats than in control, but the levels were markedly and dose-dependently increased by YGP $(p<0.05)$. Treatment of COPD rats with YGP led to significant and dose-dependent upregulation of mRNA and protein expressions of klotho ( $p$ $<0.05)$. Moreover, histologic score (index of lung damage) increased in COPD rats, relative to control, but it was dose-dependently decreased by YGP $(p<0.05)$.

Conclusion: These results suggest that YGP alleviates COPD in rats via the upregulation of klotho expression. However, the potential use of YGP for COPD still needs further clinical research.
\end{abstract}

Keywords: Chronic obstructive pulmonary disease, Klotho, Lungs, Protein expression, Yiqi Gubiao pill

\begin{abstract}
This is an Open Access article that uses a funding model which does not charge readers or their institutions for access and distributed under the terms of the Creative Commons Attribution License (http://creativecommons.org/licenses/by/4.0) and the Budapest Open Access Initiative (http://www.budapestopenaccessinitiative.org/read), which permit unrestricted use, distribution, and reproduction in any medium, provided the original work is properly credited.
\end{abstract}

Tropical Journal of Pharmaceutical Research is indexed by Science Citation Index (SciSearch), Scopus, International Pharmaceutical Abstract, Chemical Abstracts, Embase, Index Copernicus, EBSCO, African Index Medicus, JournalSeek, Journal Citation Reports/Science Edition, Directory of Open Access Journals (DOAJ), African Journal Online, Bioline International, Open-J-Gate and Pharmacy Abstracts

\section{INTRODUCTION}

Chronic obstructive pulmonary disease (COPD) is an airway inflammatory illness with high degree of recurrence [1]. The symptoms of the disease are shortness of breath and cough with sputum production, and they worsen over time. Lung damage caused by COPD is irreversible
[1]. Although largely preventable, mortality due to COPD and cost of treatment are on the rise. The prevention and management of the disease are further hindered by limited knowledge of its pathogenesis, as well as lack of therapies specifically targeting COPD [1]. The disease is often overlooked and misdiagnosed. Treatment 
strategies for COPD usually overlap with those for asthma [1].

Klotho, a protein expressed in several tissues, serves as a co-receptor for fibroblast growth factor 23 (FGF-23) [2]. Klotho possesses varied biological properties, and it has been associated with pathologies of various ailments including diabetes mellitus, cancer and Alzheimer's disease. However, its role in these conditions is yet to be fully elucidated [2].

In recent years, Traditional Chinese Medicine (TCM) has shown great promise in alleviating COPD [3]. Yiqi Gubiao pill (YGP) is an agent used in TCM for treating COPD and other pulmonary diseases. However, little or nothing is known about the precise molecular mechanism(s) involved. The aim of this study was to investigate the effect of YGP on COPD in rats, and the mechanism involved.

\section{EXPERIMENTAL}

\section{Materials}

Marlboro cigarette was purchased from Changsha Cigarette Factory. Klotho smallinterfering RNA was obtained from Shanghai GenePharma Co. Ltd. Rabbit anti-human klotho and $\beta$-actin, and horseradish peroxidase-labeled goat anti-rabbit IgG were products of Abcam. Polymerase chain reaction (PCR) primers were bought from Sangon Biotech Co. Ltd, while BCA protein assay kit was provided by Biyuntian Biotechnology Institute.

This research received approval from the Animal Ethical Committee of The Traditional Chinese Medicine Hospital Affiliated to Xinjiang Medical University (approval no. 2018736271), and was conducted according to the guidelines of Principles of Laboratory Animal Care [4].

\section{Rats}

Male SPF-grade Wistar rats $(n=60)$ aged 8 weeks and weighing $150-250 \mathrm{~g}$ (mean weight $=$ $200 \pm 50 \mathrm{~g}$ ) were obtained from Experimental Animal Center of National Clinical Research Base of Traditional Chinese Medicine Hospital Affiliated to Xinjiang Medical University, China. The rats were acclimatized to the laboratory environment for 7 days prior to commencement of the study. They were housed in metal cages under standard conditions, and were allowed access to standard feed and water at 12-h light/12-h dark cycle, average temperature of 25 $\pm 2{ }^{\circ} \mathrm{C}$ and humidity of $40-50 \%$. The study procedures were carried out according to the guidelines of Association for the Assessment and Accreditation of Laboratory Animal Care International (AAALAC).

\section{Rat grouping and treatment}

The rats were randomly assigned to 6 groups (10 rats/group): control group, COPD, low-dose YGP, medium-dose YGP, high-dose YGP and dexamethasone groups, and COPD was induced using standard methods. The rats received one dose of intra-tracheal elastase $(20 \mathrm{U} / 100 \mathrm{~g})$ on the $30^{\text {th }}$ day, and were exposed to cigarette smoke every day for $1 \mathrm{~h}$ for 90 days (10 cigarettes/time, morning and afternoon). The control group rats received equivalent volume of normal saline $(3 \mathrm{~mL} / 100 \mathrm{~g}$, once a day for 14 days) via intra-tracheal instillation. Graded doses of YGP were prepared by dissolving 100, 200 or 400 pills of Yiqi Gubiao, each in $500 \mathrm{~mL}$ of normal saline, and administering as a single dose of $3 \mathrm{~mL} / 100 \mathrm{~g}$ orally once a day. Dexamethasone was administered orally (1 $\mathrm{mg} / \mathrm{kg}$ ). The treatment lasted 14 days. Changes in lung function were monitored before and after modeling. Methacholine challenge test was used to measure airway hyperactivity [enhanced pause (Penh), tidal volume (TV), and respiratory frequency $(F)$ ].

\section{Collection of blood and tissue samples}

After 90 days of induction of COPD and 14 days of treatment, blood was collected from retroorbital plexus of each rat under mild anesthesia, and the sera were subjected to biochemical assays. The rats were euthanized via cervical dislocation and their lungs were excised for histopathological examination.

\section{Histopathological examination of lung tissues}

Excised lung tissues were fixed in $4 \%$ paraformaldehyde, paraffin-embedded, and thereafter sectioned using a microtome, followed by $H$ \& $E$ staining and examination under a light microscope. An image analyzer (Image-Pro Plus, 6.0) was used to determine histopathological changes in lung tissues, and the severity of lung damage was scored. Total histological score was taken based on a set of defined features. The higher the histologic score, the more impaired the lung.

\section{Determination of levels of klotho in serum and BALF}

The expression levels of klotho in serum and BALF were measured using their respective ELISA kits.

Trop J Pharm Res, December 2020; 19(12): 2578 


\section{Western blotting}

Total protein was extracted from cell suspension resulting from trypsinization of lung tissue (100 mg) using RIPA buffer mixed with protease inhibitor. Following determination of protein concentration with BCA method, the protein was subjected to Western blotting via SDS-PAGE, transfer to PVDF membranes, blocking of nonspecific binding, overnight incubation with $1^{\circ}$ antibodies for klotho and $\beta$-actin at $4{ }^{\circ} \mathrm{C}$, incubation with HRP-linked goat anti-rabbit IgG $2^{\circ}$ antibody, blot development with X-ray film, and Grayscale analysis with ImageJ Launcher software. $\beta$-Actin served as standard.

\section{Quantitative reverse transcription polymerase chain reaction (qRT-PCR)}

The level of expression of klotho was determined using qRT-PCR. Following extraction of total RNA from cells of each group with TriZOL, the RNA was reverse-transcribed to cDNA. Measurement of expression level of klotho was done with 1536 RT-PCR Light Cycler. Variation in the cDNA content was normalized using GAPDH. The $2^{-\Delta \Delta C t}$ method was employed for computation of protein expression levels. The primer sequences of klotho used are shown in Table 1.

Table 1: Primer sequences

\begin{tabular}{ll}
\hline Gene & Sequence \\
\hline \multirow{3}{*}{ Klotho } & Forward: 5c-CAATGGCTTCCCTCCTTTAC- \\
& 3c \\
& Reverse: 5c- \\
& AGCACACAGGTTTGCGTAGTCT-3c \\
& (512bp) \\
& Forward: 5c- \\
\multirow{3}{*}{ 3-Actin } & ACCCACACTGTGCCCATCTAT-GA-3c \\
& Reverse: 5c-CATCGGAACCGCTCATTATT \\
& CCGAT-AG-3c (296 bp) \\
\hline
\end{tabular}

\section{Agarose gel electrophoresis}

The PCR products were subjected to electrophoresis on $11.5 \%$ agarose gel and Grayscale analysis was carried out with ImageJ Launcher software. The mean optical densities of the target gene and internal reference were compared.

\section{Statistical analysis}

Data are presented as mean $\pm S D$, and they were statistically analyzed with SPSS (version 17.0). Group comparison was done with Student's $t$-test. Values of $p<0.05$ were taken as significant.

\section{RESULTS}

\section{Effect of YGP on histological changes in lung tissues}

Lung tissues of control group rats exhibited normal histology. Pulmonary alveolar wall hyperplasia and thickening (interstitial edema and accumulation of inflammatory cells), bronchial lesions, alveolar wall rupture, expansion, atrophy and necrosis were seen in the lungs of COPD rats, relative to control rats, but they were decreased by YGP exposure. Similarly, histologic score (index of lung injury) was markedly raised in COPD rats, relative to control, but it was markedly decreased by YGP $(p<0.05$; Figure 1).

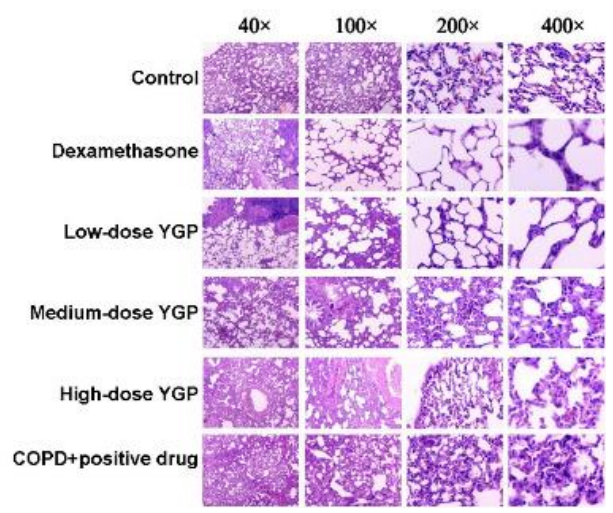

Figure 1: Effect of YGP on histological changes in lung tissues

\section{Effect of YGP on levels of klotho in rat serum}

Table 2 and Figure 2 indicate that YGP exposure markedly and dose-dependently increased the serum levels of klotho in COPD rats $(p<0.05)$.

\section{Effect of YGP on levels of klotho in rat BALF}

The BALF klotho level was significantly lower in COPD group than in control group, but it was significantly and dose-dependently increased by YGP ( $p<0.05$; Table 3 and Figure 3$)$.

Table 2: Levels of klotho in rat serum

\begin{tabular}{ll}
\hline Group & Klotho (ng/mL) \\
\hline Control & $1.09 \pm 0.29$ \\
COPD & $0.38 \pm 0.16^{\mathrm{a}}$ \\
Dexamethasone & $0.89 \pm 0.33^{\mathrm{b}}$ \\
Low-dose YGP & $0.46 \pm 0.17^{\mathrm{b}}$ \\
Medium-dose YGP & $0.51 \pm 0.28^{\mathrm{b}, \mathrm{c}}$ \\
High-dose YGP & $0.97 \pm 0.34^{\mathrm{b}, \mathrm{d}}$ \\
\hline $\mathrm{a}, \mathrm{b}, \mathrm{c}, \mathrm{d}^{\mathrm{P}}<0.05$ ( $^{\mathrm{a}} \mathrm{vs}$ control; & $\mathrm{b}$ vs COPD rats; ${ }^{\mathrm{c}} \mathrm{Vs}$ low- \\
dose YGP rats; ${ }^{\mathrm{d}}$ Vs medium-dose YGP rats)
\end{tabular}

Trop J Pharm Res, December 2020; 19(12): 2579 


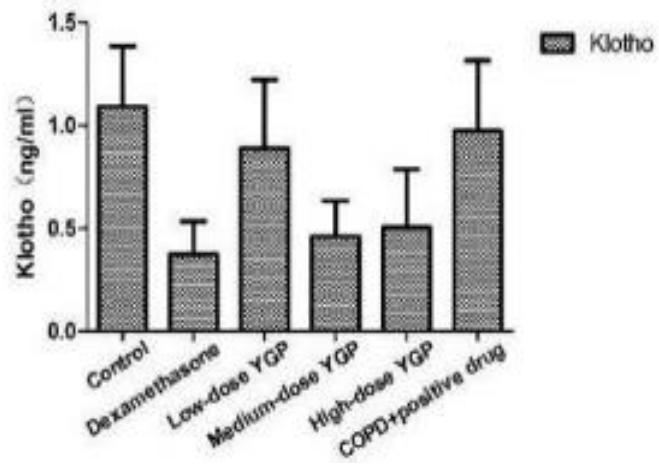

Figure 2: Levels of klotho in rat serum

Table 3: Levels of klotho in rat BALF

\begin{tabular}{lc}
\hline Group & Klotho $(\mathrm{ng} / \mathrm{mL})$ \\
\hline Control & $1.04 \pm 0.33$ \\
COPD & $0.34 \pm 0.14^{\mathrm{a}}$ \\
Dexamethasone & $0.66 \pm 0.18^{\mathrm{b}}$ \\
Low-dose YGP & $0.40 \pm 0.16^{\mathrm{b}}$ \\
Medium-dose YGP & $0.52 \pm 0.16^{\mathrm{b}, \mathrm{c}}$ \\
High-dose YGP & $0.75 \pm 0.26^{\mathrm{b}, \mathrm{d}}$ \\
\hline a,b,c,d $P<0.05$ ( $^{\mathrm{a}}$ vs control; ${ }^{\mathrm{b}}$ vs COPD rats; ${ }^{\mathrm{c}} \mathrm{vs}$ low-dose \\
YGP rats; ${ }^{\mathrm{d}}$ Vs medium-dose YGP rats)
\end{tabular}

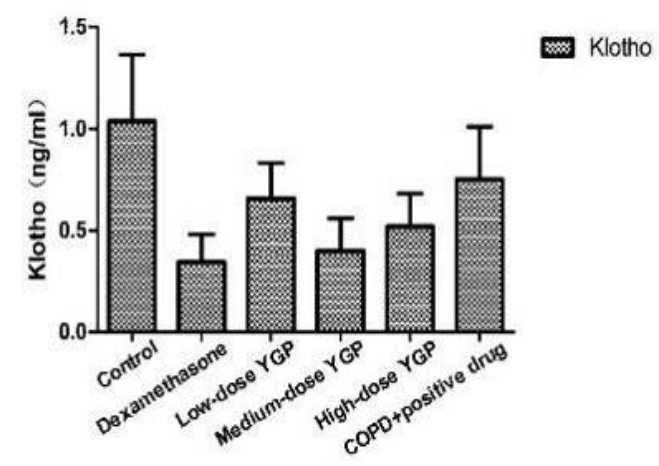

Figure 3: Levels of klotho in rat BALF

\section{Effect of YGP on klotho protein expression in rat lung tissue}

Treatment of COPD rats with YGP led to significant and dose-dependent upregulation of klotho protein expression $(p<0.05)$. These results are shown in Table 4 and Figure 4.

Table 4: Klotho protein expression in rat lung tissue

\begin{tabular}{ll}
\hline Group & Klotho (\%) \\
\hline Control & $0.57 \pm 0.09$ \\
COPD & $0.27 \pm 0.04^{\mathrm{a}}$ \\
Dexamethasone & $0.45 \pm 0.08^{\mathrm{b}}$ \\
Low-dose YGP & $0.30 \pm 0.05^{\mathrm{b}}$ \\
Medium-dose YGP & $0.37 \pm 0.06^{\mathrm{b}, \mathrm{c}}$ \\
High-dose YGP & $0.54 \pm 0.03^{\mathrm{b}, \mathrm{d}}$ \\
\hline $\mathrm{a}, \mathrm{b}, \mathrm{c}, \mathrm{d} P<0.05$ ( $^{\mathrm{a}}$ vs control; ${ }^{\mathrm{b}}$ vs COPD rats; ${ }^{\mathrm{c}}$ vs low-dose \\
YGP rats; ${ }^{\mathrm{d}}$ Vs medium-dose YGP rats)
\end{tabular}

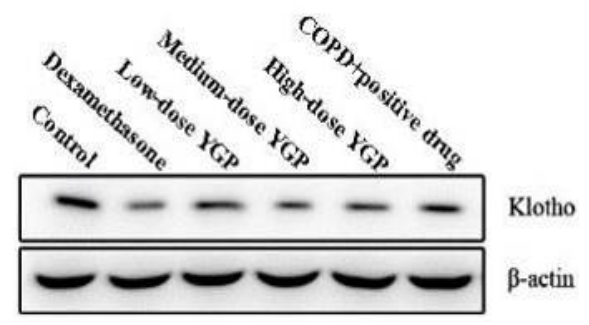

Figure 4: Klotho protein expression in rat lung tissue

\section{Effect of YGP on klotho mRNA expression in rat lung tissue}

The level of expression of klotho mRNA was significantly lower in COPD group than in control group, but it was significantly and dosedependently increased by YGP $(p<0.05$; Table 5 and Figure 5).

Table 5: mRNA expression of klotho in rat lung tissue

\begin{tabular}{ll}
\hline Group & Klotho (\%) \\
\hline Control & $1.01 \pm 0.15$ \\
COPD & $0.50 \pm 0.10^{\mathrm{a}}$ \\
Dexamethasone & $0.79 \pm 0.11^{\mathrm{b}}$ \\
Low-dose YGP & $0.61 \pm 0.14^{\mathrm{b}}$ \\
Medium-dose YGP & $0.69 \pm 0.16^{\mathrm{b}, \mathrm{c}}$ \\
High-dose YGP & $0.88 \pm 0.20^{\mathrm{b}, \mathrm{d}}$ \\
\hline $\mathrm{a}, \mathrm{b}, \mathrm{c}, \mathrm{d} P<0.05$ ( $^{\mathrm{a}}$ vs control; ${ }^{\mathrm{b}}$ vs COPD rats; ${ }^{\mathrm{c}} \mathrm{vs}$ low-dose \\
YGP rats; ${ }^{\mathrm{d}}$ Vs medium-dose YGP rats)
\end{tabular}

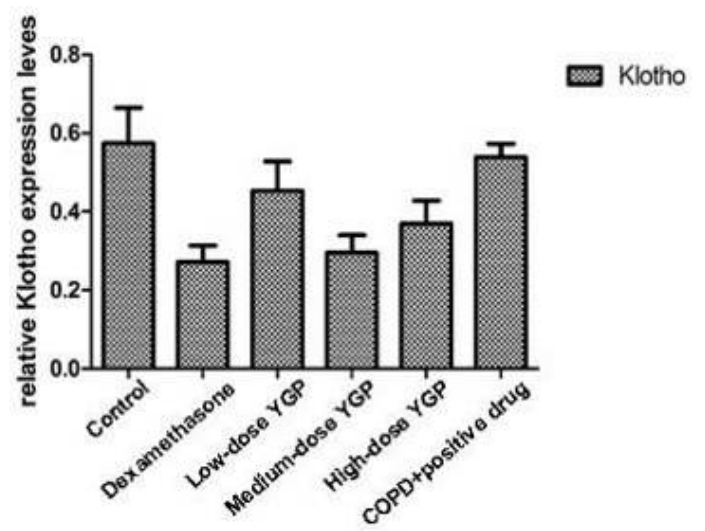

Figure 5: Klotho mRNA expression in rat lung tissue

\section{Effect of YGP on electrophoresis of PCR products}

As shown in Figure 6, the PCR product sizes were consistent with the fragment length of klotho gene (the product bands were single). The electrophoretic patterns of $28 \mathrm{~S}$ and $18 \mathrm{~S}$ were the brightest, while that of 5S was the weakest (no stripe). The single and complete stripe was consistent with that of a pure RNA sample. 

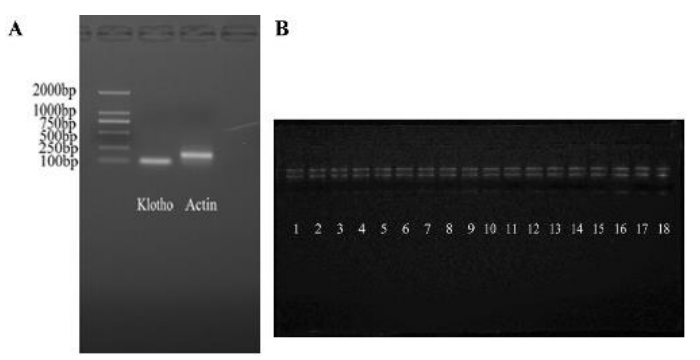

Figure 6: Effect of YGP on electrophoresis of PCR products. A: Electrophoretogram of PCR products; B: Identification of electrophoretically-separated RNA

\section{DISCUSSION}

The disease CCOPD, a progressive disorder that results in impairment of breathing, is associated with chronic inflammatory reactions and proteolysis. It is a leading factor of disability, morbidity and death in smokers. It causes destruction of the alveolar wall, impairment of lung function, and chronic inflammatory response in lung airways. The most common cause of COPD is tobacco smoke, while a smaller number of cases are due to factors such as air pollution and genetics [5]. Prolonged exposure to these stimulants triggers pulmonary inflammation, leading to obstruction of small airways and pulmonary lesions.

The clinical diagnosis of COPD relies on impaired airflow which is determined using lung function tests. Unlike asthma, poor airflow is not relieved with bronchodilators. The incidence of COPD can be minimized by avoiding exposure to the pre-disposing stimulants. This entails reducing or stopping smoking as well as enhancing ventilation. While therapy may slow down the condition from worsening, there is no known cure for COPD [6]. Moreover, COPD is associated with lung age because lung tissue is in direct contact with inhaled cigarette smokederived oxidants, free radicals and other organic components $[7,8]$. The pathogenesis of COPD is complex and the precise molecular mechanism involved has not been fully elucidated. Although it is well-established that smoking is the most crucial predisposing factor for COPD, merely 10 to $20 \%$ of habitual smokers eventually get COPD [9,10]. Animal models enhance awareness of the basic processes involved in COPD pathogenesis and therapy. Although these models merely mimic some manifestations of COPD, they are nonetheless useful for studies on mechanisms underlying human COPD.

In man, klotho is coded for by $\mathrm{KL}$ gene. Klotho comprises 3 sub-types. While a-klotho activates FGF-23, $\beta$-klotho activates FGF-19 and FGF-21.
Usually, a-klotho is implied if the sub-type is not indicated [11]. Klotho is expressed in the brain, kidneys, sex organs, pituitary, and parathyroid glands. It promotes longevity and regulates carbohydrate and mineral metabolism in nephrotic and neuronal tissues. Moreover, klotho may affect cancer and tumor suppression routes, as well as the development of many premature senescent phenotypes such as osteoporosis, stroke, CVDs and atherosclerosis in humans and mice. Emerging evidence suggest that klotho is implicated in skeletal muscle health and lifetime changes in bone mineral density [12]. The development of emphysema in klotho-knockout rat has been shown to be accompanied by increased expressions of matrix metalloproteinases $[13,14]$.

In TCM, YGP has shown great promise as a potential drug for the treatment of COPD. It strengthens spleen and lungs [15-17]. The present study investigated the influence of YGP on rats with COPD, and the mechanism involved. The results showed that treatment of COPD rats with YGP significantly and dose-dependently increased the serum and BALF levels of klotho. It also significantly and dose-dependently upregulated the mRNA and protein expressions of klotho in lung tissues of COPD rats. These results indicate that YGP may alleviate COPD via a mechanism involving the upregulation of klotho.

\section{CONCLUSION}

The findings of this investigation suggest that YGP mitigates COPD in rats via upregulation of klotho expression. However, the potential use of YGP for COPD still needs further clinical research.

\section{DECLARATIONS}

\section{Acknowledgement}

This work was supported with grants from the Natural Science Foundation of Xinjiang Uygur Autonomous Region (no. 2016D01C156).

\section{Conflict of interest}

No conflict of interest is associated with this work.

\section{Authors' contributions}

This study was done by the authors named in this manuscript, and the authors accept all liabilities resulting from claims which relate to this 
manuscript and its contents. The study was conceived and designed by Fengsen Li; Zheng $\mathrm{Li}$, Jing Wang, Dan Xu, Jing Jing, Fengsen $\mathrm{Li}$ collected and analyzed the data, while Zheng $\mathrm{Li}$ wrote the manuscript. All authors read and approved the manuscript for publication.

\section{Open Access}

This is an Open Access article that uses a funding model which does not charge readers or their institutions for access and distributed under the terms of the Creative Commons Attribution License (http://creativecommons.org/licenses/by/ 4.0) and the Budapest Open Access Initiative (http://www.budapestopenaccessinitiative.org/rea d), which permit unrestricted use, distribution, and reproduction in any medium, provided the original work is properly credited.

\section{REFERENCES}

1. Yao H, Rahman I. Current concepts on oxidative/carbonyl stress, inflammation and epigenetics in pathogenesis of chronic obstructive pulmonary disease. Toxicol Appl Pharmacol 2011; 254(2): 72-85.

2. Chen H, Li QY, LU S. Research progress of JAK / STAT signaling pathway regulated by traditional Chinese Medicine. Chin J Integr Med Cardio Cerebrovasc Dis 2016; 14(19): 2258-2262.

3. Mitzner W. Emphysema--a disease of small airways or lung parenchyma? N Engl J Med 2011; 365(17): 16371639.

4. World Health Organization. Principles of laboratory animal care. WHO Chron 1985; 39: 51-56.

5. Yang SR, Chida AS, Bauter MR, Shafiq N, Seweryniak K, Maggirwar SB, Kilty I, Rahman I. Cigarette smoke induces proinflammatory cytokine release by activation of NF-B and posttranslational modifications of histone deacetylase in macrophages. Am J Physiol Lung Cell Mol Physiol 2016; 291(1): 46-57.

6. Imai M, Ishikawa K, Matsukawa $N$, Kida I, Ohta J, Ikushima M, Chihara Y, Rui X, Rakugi H, Ogihara $T$. Klotho protein activates the PKC pathway in the kidney and testis and suppresses 25-hydroxyvitamin D3 1alpha-hydroxylase gene expression. Endocrine 2004; 25(3): 229-234.

7. Kode A, Yang SR, Rahman I. Differential effects of cigarette smoke on oxidative stress and proinflammatory cytokine release in primary human airway epithelial cells and in a variety of transformed alveolar epithelial cells. Respir Res 2016; 7: 132-152.

8. Moodie FM, Marwick JA, Anderson CS, Szulakowski P, Biswas SK, Bauter MR, Kilty I, Rahman I. Oxidative stress and cigarette smoke alter chromatin remodeling but differentially regulate NF-B activation and proinflammatory cytokine release in alveolar epithelial cells. FASEB J 2004; 18(15): 1897-1899.

9. Zhao Y, Banerjee S, Dey N, LeJeune WS, Sarkar PS, Brobey $R$, Rosenblatt KP, Tilton RG, Choudhary $S$. Klotho depletion contributes to increased inflammation in kidney of the $d b / d b$ mouse model of diabetes via RelA (Serine) 536 phosphorylation. Diabetes 2011; 60(7): 1907-1916.

10. Banerjee S, Zhao Y, Sarkar PS, Rosenblatt KP, Tilton $R G$, Choudhary S. Klotho ameliorates chemically induced endoplasmic reticulum (ER) stress signaling. Cell Physiol Biochem 2013; 31(4-5): 659-672.

11. Thurston RD, Larmonier $C B$, Majewski $P M$, Ramalingam $R$, Midura-Kiela $M$, Laubitz $D$, Vandewalle A, Besselsen $D G$, Mühlbauer $M$, Jobin $C$. Tumor necrosis factor and interferon-gamma down-regulate Klotho in mice with colitis. Gastroenterology 2010; 138(4): 1384-1394.

12. Durham AL, McLaren A, Hayes BP, Caramori G, Clayton CL, Barnes PJ, Chung KF, Adcock IM. Regulation of Wnt4 in chronic obstructive pulmonary disease. FASEB J 2013; 27(6): 2367-2381.

13. Pickens SR, Chamberlain ND, Volin MV, Pope RM, Mandelin AM, Shahrara S. Characterization of CCL19 and CCL21 in rheumatoid arthritis. Arthritis Rheum 2011; 63(4): 914-922.

14. Yao X, Yuan C, Zhang J, Zhou L, Huang M, Adcock I, Barnes P. Klotho: An important protein in the formation and development of emphysema. Chin $\mathrm{J}$ Mater Res 2012; 21(2): 119-125.

15. Li FS, XU D, Gao Z, Li Z, Jing J, Zhang YL, Wang J. Clinical Study on Yiqi Gubiao Pill Combined with Pingchuan External Application Ointment for Treatment of Patients with Chronic Obstructive Pulmonary Disease at Stable Stage. Chin J Inf Tradit Chin Med 2017; 24(6): 22-26.

16. Xiong B, Qian HN. Influence of Yiqi Jianpi Prescription on JAK1, STAT1 and SOCS1 in Brain of Rats with Spleen Deficiency. Chin Arch Tradit Chin Med 2013; 31(7): 1543-1547.

17. Li Dong, Lixia Yang, Fengsui Liu, Haitao Zhan, Xinwei Chen. Farrerol ameliorates diabetic hepatopathy in rat model of type 2 diabetes mellitus via modulation of oxidative inflammatory stress. Trop J Pharm Res 2020; 19(1): 71-76. 